\title{
Teriflunomide and monomethylfumarate target HIV-induced neuroinflammation and neurotoxicity
}

\author{
Björn Ambrosius ${ }^{1 *+} \mathbb{D}$, Simon Faissner ${ }^{1,2+}$, Kirsten Guse ${ }^{1,3}$, Marec von Lehe ${ }^{4}$, Thomas Grunwald ${ }^{5}$, Ralf Gold ${ }^{1}$, \\ Bastian Grewe ${ }^{6}$ and Andrew Chan ${ }^{3 *}$
}

\begin{abstract}
HIV-associated neurocognitive disorders (HAND) affect about 50\% of infected patients despite combined antiretroviral therapy (CART). Ongoing compartmentalized inflammation mediated by microglia which are activated by HIV-infected monocytes has been postulated to contribute to neurotoxicity independent from viral replication. Here, we investigated effects of teriflunomide and monomethylfumarate on monocyte/microglial activation and neurotoxicity. Human monocytoid cells (U937) transduced with a minimal HIV-Vector were co-cultured with human microglial cells (HMC3). Secretion of pro-inflammatory/neurotoxic cytokines (CXCL10, CCL5, and CCL2: $p<0.001$; IL6: $p<0.01)$ by co-cultures was strongly increased compared to microglia in contact with HIV-particles alone. Upon treatment with teriflunomide, cytokine secretion was decreased (CXCL10, 3-fold; CCL2, 2.5-fold; IL-6, 2.2-fold; $p<0$. $001)$ and monomethylfumarate treatment led to 2.9-fold lower CXCL10 secretion $(p<0.001)$. Reduced toxicity of co-culture conditioned media on human fetal neurons by teriflunomide $(29 \%, p<0.01)$ and monomethylfumarate $(27 \%, p<0.05)$ indicated functional relevance. Modulation of innate immune functions by teriflunomide and monomethylfumarate may target neurotoxic inflammation in the context of HAND.
\end{abstract}

Keywords: HIV-associated neurocognitive disorder, HAND, Glial activation, Microglia, Neuroinflammation, Leflunomide, Dimethyl fumarate

\section{Introduction}

Human immunodeficiency virus (HIV)-infected patients suffer serious complications, of which the pathogenesis of HIV-associated neurocognitive disorders (HAND) is one of the least understood. Since the introduction of combined antiretroviral therapy (cART) in the early 1990s, higher prevalence of the less severe phenotypes of HAND were reported $[1,2]$. One key hypothesis to explain the occurrence of HAND despite inhibition of viral replication is the "bystander hypothesis". It postulates that microglia become activated by HIV-infected monocytes and $\mathrm{T}$ cells, which have entered the brain

\footnotetext{
*Correspondence: Bjoern.Ambrosius@ruhr-uni-bochum.de;

Andrew.Chan@insel.ch

${ }^{\dagger}$ Equal contributors

'Department of Neurology, St. Josef-Hospital, Ruhr-University Bochum, Gudrunstr. 56, 44791 Bochum, Germany

${ }^{3}$ Department of Neurology, University Hospital Bern and University of Bern, Bern, Switzerland

Full list of author information is available at the end of the article
}

early during infection $[3,4]$. As a consequence, microglia release pro-inflammatory and neurotoxic factors that induce neurotoxicity [5]. Several studies demonstrated that immune activation of monocytes and microglia contribute to neurodegeneration in the context of HAND [4, 6-9]. Earlier results of our group stressed the importance of monocyte involvement for full microglial activation. HIV-transduced monocytes act as amplifier of microglial activation and neurotoxicity [4]. We also demonstrated that a panel of microglia-derived cytokines was differentially regulated in vitro (CXCL10, CCL5, and IL-6). These cytokines were associated with markers of early neurodegeneration in cerebrospinal fluid (CSF) of HIV-infected, yet neurocognitively not symptomatic patients [4]. Thus, therapeutic modulation of innate immune cell activation may hypothetically also affect neurodegeneration in the context of HAND.

Different agents have been demonstrated to affect microglial and monocyte activation in the context of 
autoimmune neuroinflammation. Teriflunomide (Teri) mainly inhibits de novo pyrimidine synthesis in mitochondria by acting on dihydroorotate dehydrogenase (DHODH), which leads to inhibition of $\mathrm{T}$ and $\mathrm{B}$ cell proliferation [10]. In addition, DHODH-independent effects with decreased release of pro-inflammatory cytokines from monocytes are described [11]. Fumaric acid esters lead to the intranuclear translocation of nuclear factor 2 (Nrf2). They enhance the expression of anti-oxidative enzymes and decrease pro-inflammatory cytokine secretion by microglia during experimental autoimmune neuroinflammation [12, 13]. In HIV-infected macrophages in vitro, monomethylfumarate (MMF) decreases pro-inflammatory cytokine release and induces an antioxidant response $[14,15]$. However, the effect of either Teri or MMF on monocyte/microglia interaction in the context of HAND remains elusive. Here, we set out to investigate the role of Teri and MMF in the context of microglial activation and neurotoxicity triggered by HIV-infected monocytes.

\section{Methods}

\section{Cell culture}

Human microglial cell line 3 (HMC3, Dr. J. Pocock, University College London) was produced by transfecting human embryonic brain-derived macrophages with the large $\mathrm{T}$ antigen of the simian virus 40 . The cell line expresses microglial and macrophage surface markers [16]. Similar to primary microglia, these cells show a distinct response of cytokines and chemokines in contact to pathogens [17] and were already described in the context of HIV [18]. Cells were cultured in Minimum Essential Media (MEM) (Thermo Fisher Scientific, Darmstadt, Germany), supplemented with $10 \%$ fetal calf serum (FCS) (Sigma-Aldrich, Taufkirchen, Germany) and 100 units $/ \mathrm{ml} \mathrm{(U/ml)} \mathrm{penicillin/streptomycin} \mathrm{(Pen/}$ Strep, Invitrogen, Darmstadt, Germany) in T-75 flasks

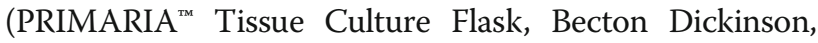
Heidelberg, Germany). Cells were passaged at a confluence of $90 \%$. For experiments, cells were plated in 96-well plates (10,000 cells/well) (Sarstedt, Nümbrecht, Germany) $24 \mathrm{~h}$ before co-culture experiments or treatment with pharmacological substances.

Primary human microglia were isolated from patients with intractable epilepsy, as previously described [19]. Cells were plated at the same density as HMC3 cells.

U937 cells (further referred to as monocytoid cells, Sigma Aldrich, München, Germany) were derived from a patient with generalized histiocytic lymphoma [20]. Cells were cultured in RPMI-1640 (Thermo Fisher Scientific), supplemented with 10\% FCS and $100 \mathrm{U} / \mathrm{ml}$ Pen/Strep. For transduction, 50,000 monocytoid cells were seeded in 24well plates (Sarstedt, Nümbrecht, Germany) and incubated with HIV particles as previously described [4].
Human fetal neurons (HFN) were isolated from 18-20-week-old brains that were obtained from therapeutically aborted fetuses as previously described [21]. Cells were plated in MEM supplemented with $10 \%$ fetal bovine serum, $1 \mu \mathrm{M}$ sodium pyruvate, $10 \mu \mathrm{M}$ glutamine, $\times 1$ nonessential amino acids, $0.1 \%$ dextrose and $1 \%$ penicillin/ streptomycin (HFN-complete medium; Invitrogen, Burlington, Canada). Cells were plated in poly-L-ornithine coated $(10 \mu \mathrm{g} / \mathrm{ml})$ T75 flasks $\left(5 \times 10^{7}\right.$ cells in $25 \mathrm{ml}$ media $)$ and treated with three cycles of $25 \mu \mathrm{M}$ cytosine arabinoside (Sigma-Aldrich, St. Louis, MO) to kill dividing astrocytes. For experiments, HFN were plated in coated 96-well plates $(100,000$ cells/well in $100 \mu \mathrm{l}$ medium). After $48 \mathrm{~h}$ media was changed to MEM media supplemented with $1 \%$ Pen/Strep for $5 \mathrm{~h}$. At this point, the media was removed and cells were treated with conditioned media of HMC3 cells or HMC3/monocytoid cells co-cultures. After $48 \mathrm{~h}$, cells were stained with propidium iodide (PI, $1 \mu \mathrm{g} / \mathrm{ml}$; Sigma-Aldrich), fixed with $4 \%$ PFA, and stored in PBS at $4{ }^{\circ} \mathrm{C}$.

Preparation of viral particles and transduction of target cells All necessary transduction controls for the investigation of the role of monocytoid cells in contact with viral particles were investigated in detail by our group previously [4]. Different viral particles which were either not able to fuse with monocytoid cells ("HIV-fusion-deficient"), did not contain viral RNA ("HIV empty"), or were deficient of viral enzymes ("HIV-pol-deficient") were employed to delineate the essential steps of microglial/monocyte activation. In particular, viral particles which consisted of gag but which did not contain viral RNA were used to exclude that the process of transduction is responsible for activation and neurotoxicity ("HIV empty") [4].

Preparation of viral particles after transfection of HEK293T cells as well as characteristics of the HIV vector have been described previously [4]. Transfections were conducted with the calcium-phosphate coprecipitation method [22]. As an additional control for HIV vector particles, supernatants of HEK293T cells treated with transfection reagent were used. Viral particles were produced as self-inactivating HIV particles [23] and contain HIV RNA with enzymatic equipment for reverse transcription and integration into the genome of monocytoid cells [4]. For this, HIV CS-CG was co-transfected with $\mathrm{HGP}^{\text {syn }}$, pcRev, pcTat, and pseudotyped with pHIT-G (further referred to as HIV vector). HIV CS-CG encodes for a minimal HIV genome, which is packed into the viral particles and contains a GFP-sequence [4].

Due to the time needed for viral gene expression in host cells [24], transduction efficiency was analyzed by flow-cytometry $48 \mathrm{~h}$ after transduction based on the number of GFP-positive cells. Transduction of monocytoid cells 
with the HIV vector led to consistent transduction rates of $4-6 \%(4.3 \pm 0.21$ (mean \pm SEM, $n=3))$ similar to the rate of HIV-infected monocytes in the CNS of infected patients [25].

Viability of monocytoid cells was determined via FACS using 7AAD (eBioscience, Frankfurt a. M., Germany, $0.5 \mu \mathrm{l} / 50,000$ cells). Viability of HMC3 was determined using $4 \mu \mathrm{g} / \mathrm{ml}$ bisBenzimide $\mathrm{H} 33342$ (Sigma-Aldrich, Taufkirchen, Germany) for $2 \mathrm{~h}$, followed by 7AAD $(0.5 \mu \mathrm{l} /$ well). Mean fluorescence intensity (IX51, Olympus, Hamburg, Germany) was analyzed using Image (NIH, Bethesda, USA).

\section{Co-culture and pharmacological treatment}

HIV vector-transduced monocytoid cells were treated with Teri (10 and $30 \mu \mathrm{M})$ or $\operatorname{MMF}(10,30$, and $100 \mu \mathrm{M}$ ) dissolved in dimethlysulfoxide (DMSO) immediately before the application to microglia in a 1:2 ratio. This experimental design was chosen to ensure that the integrity of the microglial cell layer was not influenced by additional pipetting steps which may alter activation status. The cells were co-cultured with either Teri or MMF for $24 \mathrm{~h}$. Supernatants were collected, centrifuged (4000 rpm, $5 \mathrm{~min}$ ) and stored at $-80{ }^{\circ} \mathrm{C}$ for further analysis. Supernatants of untreated co-cultures served as controls. To investigate an effect of pharmacological agents exclusively on microglia, microglia in the presence of viral particles were treated with Teri or MMF.

\section{Cytokine Bead Array}

Cytokine secretion by the monocytoid cell/microglial coculture was analyzed using the FACS-based Cytokine Bead Array (CBA) (Becton Dickinson, Franklin Lakes, USA; FACS Canto II). Selection of cytokines followed our previous study where CXCL10, CCL5, CCL2, and IL-6 were differentially regulated upon co-culture of HIV vector-transduced monocytoid cells with microglia. Furthermore, CXCL10, CCL5, and IL-6 correlated with neurofilament heavy chain in the CSF of $\mathrm{HIV}^{+}$patients [4]. In addition, we also analyzed IFN- $\gamma$, IL-1 $\beta$, IL-4, and IL-10 (500 events per cytokine). Further analysis was performed using the software FCAP Array v.3.

\section{Immunocytochemistry and microscopy of HFN}

After PI staining and PFA fixation, immunofluorescence staining was performed using blocking buffer for $1 \mathrm{~h}$. Incubation with anti-microtubuli associated protein-2 (MAP-2) primary antibody (dilution 1:1000; Sigma, Oakville, Canada) overnight $\left(4{ }^{\circ} \mathrm{C}\right)$, followed by Alexa Fluor 488 (dilution 1:250, Invitrogen, Burlington, Canada), and staining of nuclei with Hoechst S769121 was performed thereafter. Images were taken at $\times 10$ magnification (ImageXpress ${ }^{\circ}$, Molecular Devices, Sunnyvale, CA). Analysis was performed using MetaXpress ${ }^{\circ}$ with the algorithm "multiwavelength cell scoring" and data from nine sites/well were averaged to one data point. Dead neurons will not adhere after fixation, and thus, the number of remaining neurons correlates with cell death [26]. To correct for adherent, but dead neurons, the few adherent PI-positive neurons (MAP- $2^{+} \mathrm{PI}^{+} ; 0.1 \%$ in average of all conditions) were subtracted from $\mathrm{MAP}-2^{+} \mathrm{PI}^{-}$cells, representing surviving neurons. $\mathrm{H}_{2} \mathrm{O}_{2}(3 \mu \mathrm{M})$ was used as a positive control to induce cell death in neurons.

\section{Statistical analysis}

Experiments were performed in triplicates, if not otherwise stated. Data were statistically analyzed using a parametric one-way ANOVA with post hoc analyses as indicated in the figure legends. Statistical significance was shown as ${ }^{*} p<0.05 ; * * 0<0.01 ; * * * 0.001$; and ${ }^{* * * * *} p<0.0001$ (GraphPad Prism v.7, GraphPad Software, USA).

\section{Results}

Highest secretion of pro-inflammatory and neurotoxic cytokines occurs only after contact of microglia with HIV-infected monocytoid cells

We first investigated if HIV-transduced monocytoid cells are mandatory for broad microglial activation or whether microglial contact with HIV vector without involvement of monocytes would suffice. As depicted in Additional file 1: Figure S1, the strongest secretion of CXCL10, CCL5, CCL2, and IL-6 was found in microglia in direct contact with HIV-transduced monocytoid cells $(p<0.001)$. In comparison, all control conditions (HIV-transduced monocytoid cells alone, microglia alone with HIV vector, co-culture of microglia with non-infected monocytoid cells, Additional file 1: Figure S1) showed significantly lower cytokine release. HMC3 microglia in contact with HIV vector alone showed higher release of CXCL10 and IL-6 than HMC3 microglia alone (CXCL10 $p<0.001$; IL-6 $p<0.001)$. CCL5 and CCL2 were not altered. Thus, in line with our previous data [4], the strongest chemokine/cytokine secretion occurred only after contact of microglia with HIV-infected monocytoid cells but not with viral particles alone. Secretion of CXCL10, CCL5, CCL2, and IL-6 was differentially regulated. Other cytokines (IFN- $\gamma$, IL- $1 \beta$, IL-4, and IL-10) were not detected (data not shown).

\section{Teri and MMF reduce activation of monocyte/microglia co-culture}

Next, we examined whether Teri and MMF can modulate the cytokine secretion in the co-culture setting. Teri decreased the cytokine secretion in microglia exposed to HIV vector-transduced monocytoid cells in a dose dependent fashion (Teri $30 \mu \mathrm{M}$, CXCL10; 3-fold, CCL2; 2.5 -fold, IL-6; 2.2-fold; $p<0.001$ ) (Fig. $1 \mathrm{a}-\mathrm{d}$ ), whereas CCL5 was not altered (B). One hundred microliter MMF decreased secretion of CXCL10 (2.9-fold; $p<0.001)$ 

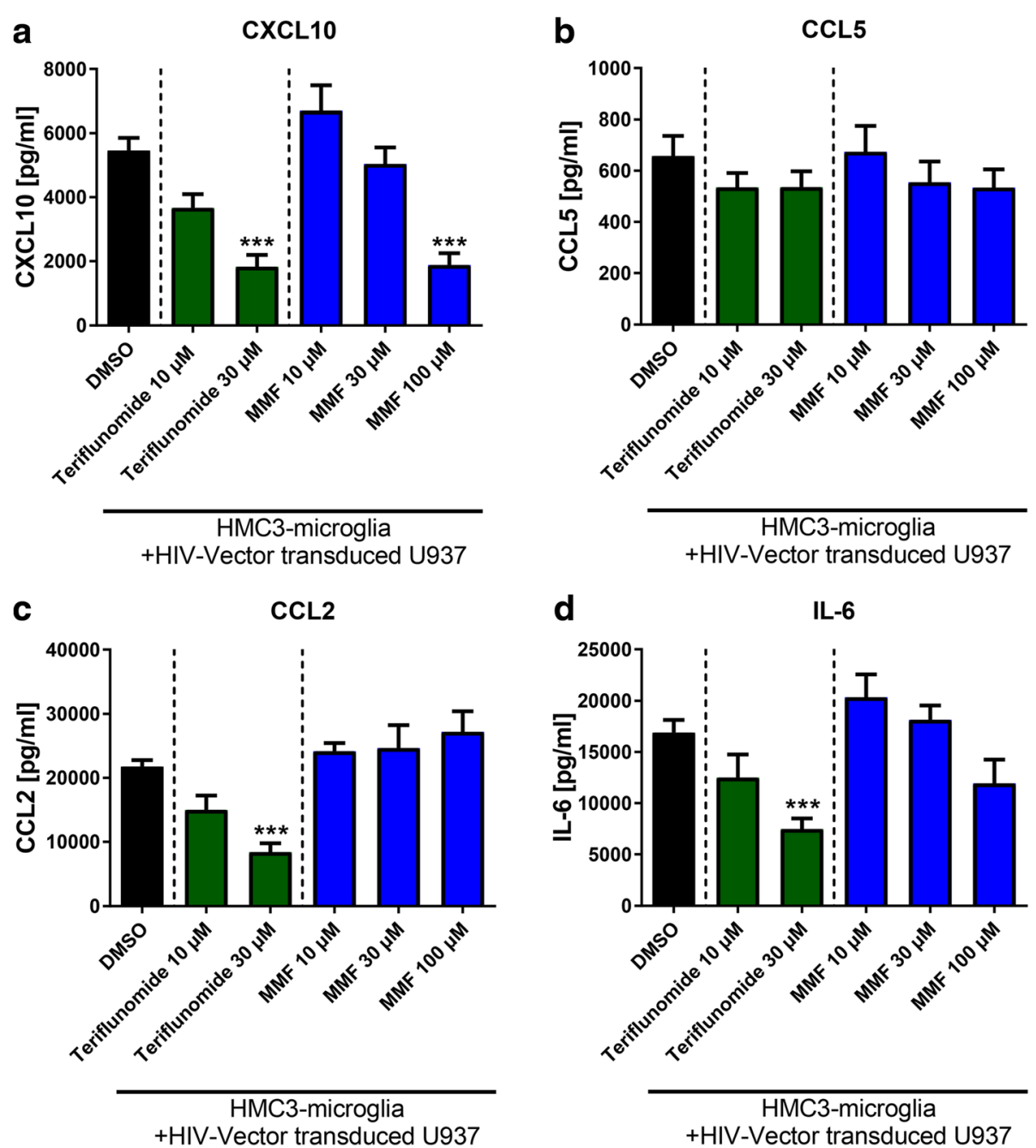

Fig. 1 Teri and MMF reduce cytokine secretion of monocyte/microglia co-culture. Treatment of the co-culture of HMC3 microglial cells with HIV vector-transduced monocytoid cells (U937) with Teri or MMF. Shown are three independent experiments performed in triplicates. Significance is observed in comparison to microglia in co-culture with HIV vector transduced monocytoid cells. DMSO was used as a solvent and used in the control condition HIV vector. Data are depicted as mean \pm SEM. $\mathbf{a}, \mathbf{c}$, and $\mathbf{d}$ : Statistical analysis was performed using one-way ANOVA (<0.0001) with Tukey's multiple comparisons test as post hoc analysis. b No significant difference. ${ }^{* *} p<0.001$

(Fig. 1a) but did not alter the release of CCL5, CCL2, and IL-6 (Fig. 1b-d). DMSO used as solvent did not have an effect on cytokine release (data not shown). Teri $(30 \mu \mathrm{M})$ or MMF $(100 \mu \mathrm{M})$ in concentrations used for the coculture experiments did not induce cell death in monocytoid cells or microglia (Additional file 2: Figure S2).

Similar, albeit restricted effects of pharmacological treatment, were also observed in the absence of monocytoid cells. In microglia in contact with HIV vector particles, treatment with $100 \mu \mathrm{M}$ MMF led to a reduction of CXCL10 (4.6-fold) and IL-6 (2.8-fold, all $p<0.001$; Additional file 1: Figure S1A and D). In contrast, $30 \mu \mathrm{M}$ Teri did not alter the secretion of CXCL10, CCL5, and IL-6 (Additional file 1: Figure S1).

To rule out that the effects were restricted to HMC3 microglia, data were further corroborated using primary human microglia with HIV vector-transduced monocytoid cells (Fig. 2). Similar to experiments performed with HMC3 microglia, the co-culture of primary microglia with HIV vector transduced monocytoid cells showed higher secretion of CXCL10 $(p<0.01)$, CCL5, CCL2, and IL-6 (all $p<0.001$ ) compared to non-transduced control conditions. Also, the control condition with the transfection reagent alone confirmed that the transfection reagent was not responsible for activation (CXCL10 $p<$ 0.05; CCL5 $p<0.01$; CCL2 $p<0.001$; and IL-6 $p<0.01$ in comparison to HIV vector). Treatment with MMF $(100 \mu \mathrm{M})$ reduced CXCL10 (7.7-fold, $p<0.05$; Fig. 2a) and CCL5 secretion (1.6-fold, $p<0.01$; Fig. 2b) whereas CCL2 and IL-6 were not altered (Fig. 2c, d). Therefore, data generated using $\mathrm{HMC} 3$ mimic the response of primary microglia. 


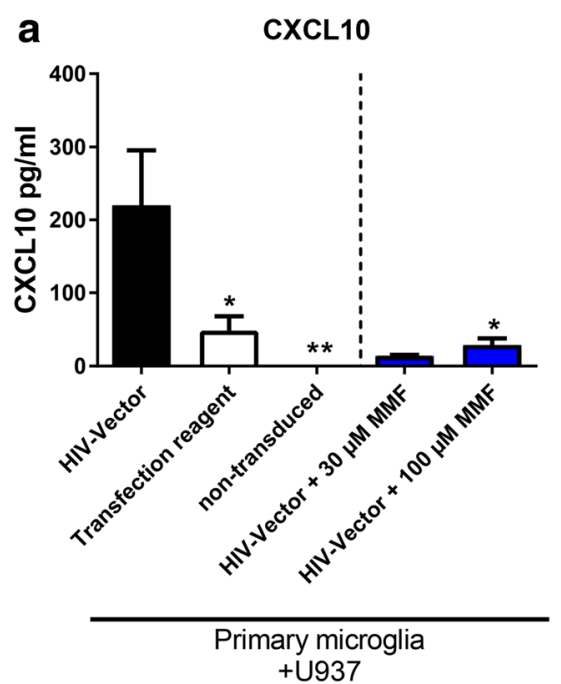

C

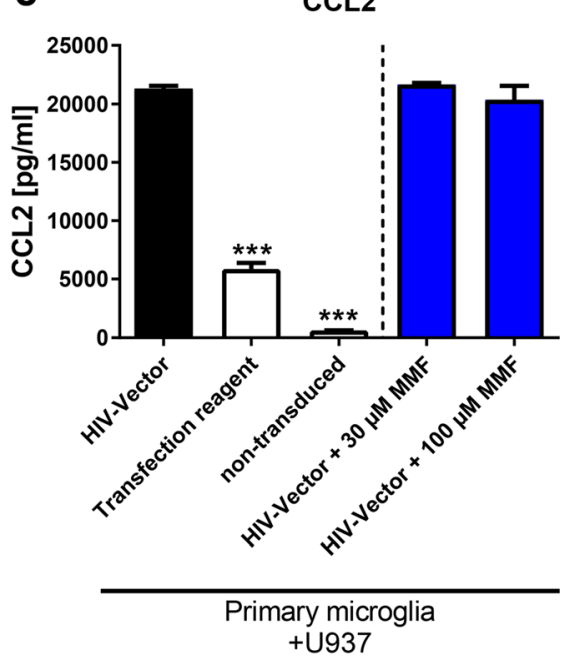

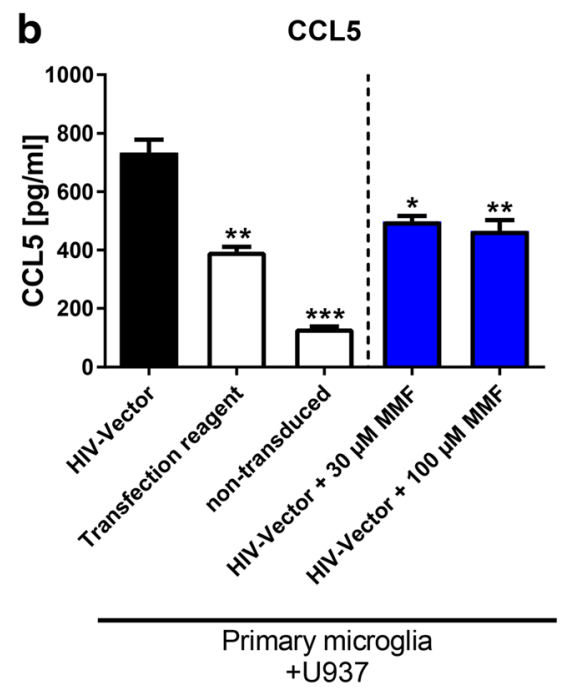

d

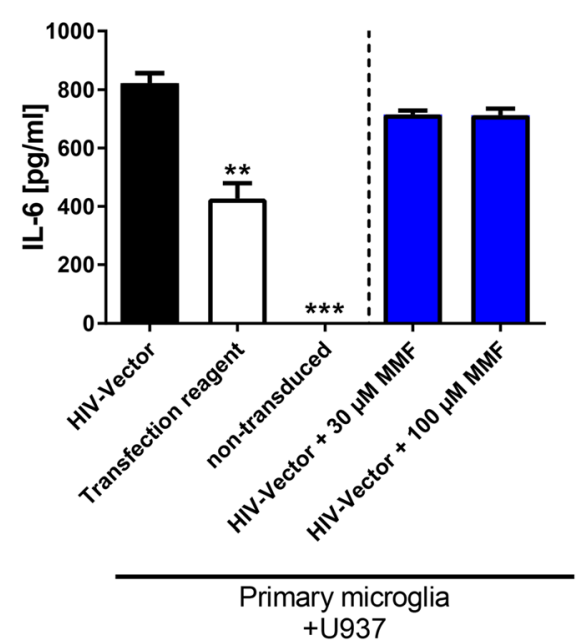

Fig. 2 Reduced cytokine secretion in primary microglia co-culture upon treatment with MMF. MMF treatment of primary microglia in co-culture with HIV vector-transduced monocytoid cells reduced the release of CXCL10 and CCL5 (a, b), whereas secretion of CCL2 and IL-6 were not altered (c, d). Monocytoid cells (U937) were added after transduction (HIV-Vector) or non-transduced (non-transduced) to primary microglia. Transfection reagent was used as additional control. Shown are one to two experiments in duplicates or triplicates. Significant differences are observed in comparison to microglia in co-culture with HIV vector-transduced monocytoid cells ${ }^{* * *}$ ). Data are presented as mean \pm SEM. Statistical analysis was performed using one-way ANOVA $(<0.0001)$ with Tukey's multiple comparison test as post hoc analysis. ${ }^{*} p<0.05 ;{ }^{* *} p<0.01 ;{ }^{* * *} p<0.001$

Supernatants of Teriflunomide and MMF treated monocyte/ microglia co-cultures reduce HIV-mediated neurotoxicity To investigate if pharmacological treatment also has functional effects on neuronal viability, we analyzed monocyte/microglia-induced neurotoxicity using human fetal neurons (HFN). Neither Teri nor MMF altered neuronal viability (data not shown). Supernatants from microglia exposed to HIV vector in the absence of monocytoid cells did not elicit neuronal cell death (Fig. 3a). In contrast, supernatants derived from co-culture of microglia with HIV vector-transduced monocytoid cells strongly induced cell death after $48 \mathrm{~h}$ (31\% fewer surviving neurons than microglia with non-transduced monocytoid cells, $p<0.0001$; Fig. 3a, c). Treatment with $10 \mu \mathrm{M}$ Teri
(11.2\% fewer neurons, $p<0.01), 10 \mu \mathrm{M}$ MMF $(14.1 \%$ fewer neurons, $p<0.05)$ and $30 \mu \mathrm{M}$ MMF $(12.6 \%$ fewer neurons, $p<0.05$ ) led to significantly enhanced neuronal viability in comparison to supernatants derived from the co-culture of microglial cells with HIV vector transduced monocytoid cells. Higher concentrations of Teri $(30 \mu \mathrm{M})$ and MMF $(100 \mu \mathrm{M})$ did not result in increased neuronal viability. $\mathrm{H}_{2} \mathrm{O}_{2}(3 \mu \mathrm{M})$ was used as positive control and induced complete neuronal cell death.

\section{Discussion}

In this study, we investigated the effect of Teri and MMF in the context of HIV-mediated monocyte/microglial 


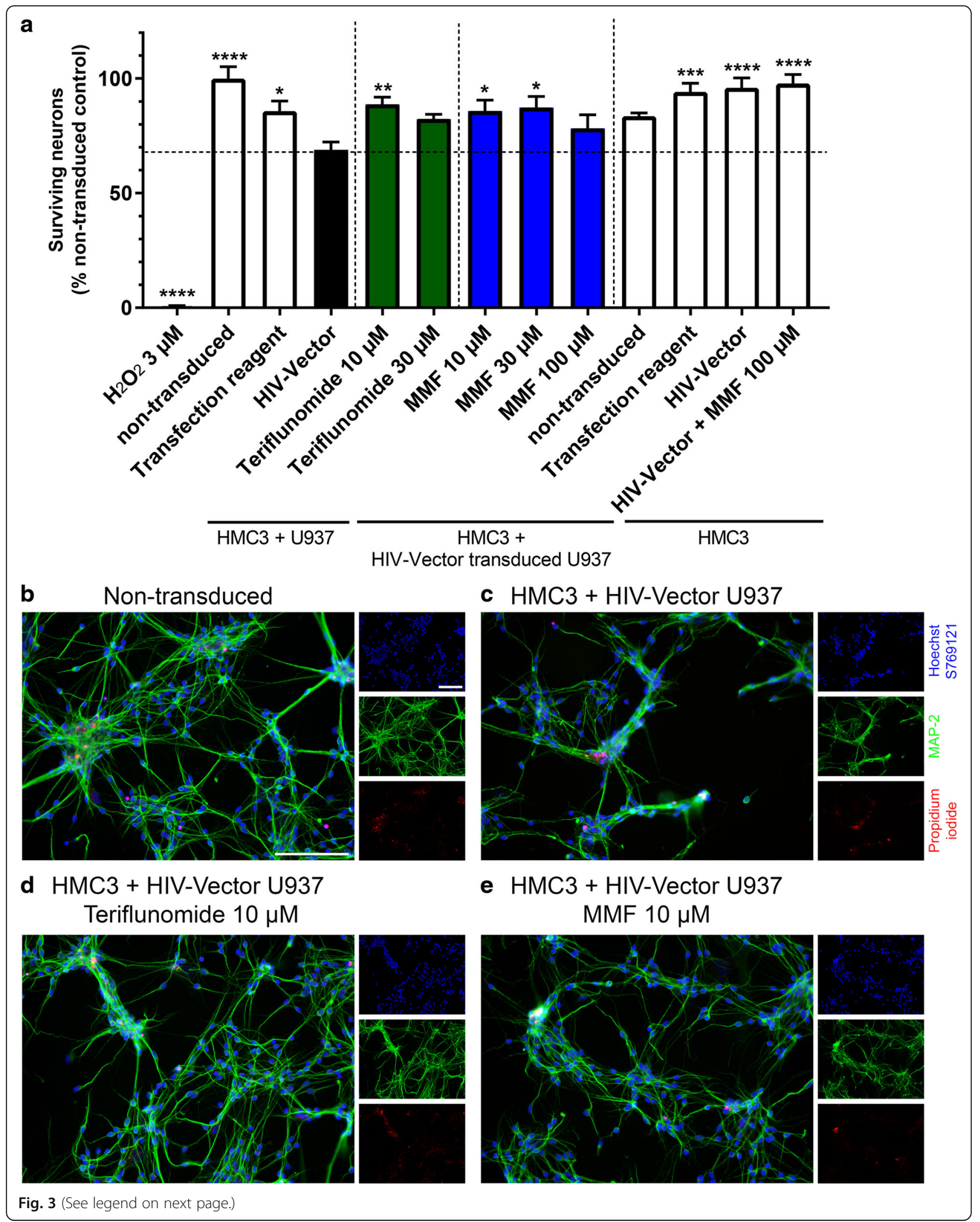


(See figure on previous page.)

Fig. 3 Teri and MMF preserve neuronal viability. Treatment of human fetal neurons (HFN) with conditioned media of HMC3 microglia co-cultured with HIV vector-transduced monocytoid cells induced cell death after $48 \mathrm{~h}(\mathbf{a}, \mathbf{c})$ compared to the non-transduced control condition ( $p<0.0001$; (b)). Neurotoxicity was significantly reduced upon treatment with $10 \mu \mathrm{M}$ Teri $(p<0.01)(\mathbf{d})$ and $10 \mu \mathrm{M}(p<0.05)(\mathbf{e})$ or $30 \mu \mathrm{M} \mathrm{MMF}(p<0.05)$. Staining for microtubuli-associated protein (MAP)-2 (green), nuclei (Hoechst S769121, blue) and propidium iodide (red). Pictures are shown in $\times 20$ magnification, the scale bar represents $100 \mu \mathrm{M}$. Shown are data generated with conditioned media of three independent experiments performed in triplicates (a). Statistics was performed using one-way ANOVA with Sidak's multiple comparisons test as post hoc analysis. MAP $-2^{+} \mathrm{PI}^{+}$cells were subtracted from MAP- $2^{+} \mathrm{PI}^{-}$cells, thus only showing surviving neurons. Data are normalized to the control condition HMC3 + non-transduced monocytoid cells and are shown as mean \pm SEM. Significance is shown compared to conditioned media of the HIV vector transduced co-culture condition ("HIV vector"). ${ }^{*} p<0.05$; ${ }^{* *} p<0.01 ;{ }^{* * *} p<0.001 ;{ }^{* * * *} p<0.0001$

inflammation due to their well characterized antiinflammatory properties. The ultimate goal was to reduce inflammation-related neurotoxicity. We demonstrate that Teri and MMF lead to reduced chemotactic and proinflammatory cytokine secretion in a co-culture system of microglia with HIV-transduced monocytoid cells. This was associated with reduced neurotoxicity of supernatant in human fetal neurons.

One limitation of this study is the use of monocytoid and microglial cell lines. However, our experiments performed with primary adult human microglia corroborated data generated using the HMC3 microglia cell line. Also, similar to the results obtained with primary embryonic microglia [4], HMC3 secrete more CXCL10, CCL5, CCL2, and IL-6 in contact with HIV vector-transduced monocytoid cells than after contact with HIV particles alone. This finding as well as lack of neurotoxicity of microglia exposed to HIV particles without monocytes is in line with the bystander hypothesis.

Microglial activation in our experimental setting is highly regulated. Mechanistically, viral RNA in monocytoid cells is required for full activation and subsequent neuronal cell death [4]. Inhibition of subsequent steps following insertion of viral RNA into monocytoid cells did not reduce microglial activation [4]. We also excluded that the process of transduction itself is responsible for activation. This agrees with findings that cART treatment does not downregulate cytokine secretion in the CNS of HIV-infected patients [27].

Enhanced CNS inflammation in HIV infection with elevated concentrations of mainly pro-inflammatory cytokines and chemokines is described in patients with HAND [7]. Differentially regulated cytokines investigated in this study are associated with the neurodegenerative markers neurofilament heavy and light chain in CSF of HIV-infected patients with and without neurocognitive impairment. This suggests ongoing inflammation with clinically silent neurodegeneration already during early stages of the disease $[4,9]$.

Our experimental setting does not allow us to distinguish whether treatment effects are related to interactions with microglia, HIV-transduced monocytes or both. Both Teri and MMF have anti-inflammatory effects, but with different targets. However, it remains difficult to draw definite conclusions as both agents may have a differential impact in vivo. Rather, our work suggests that therapeutic modulation of innate immune cell function using Teri or MMF may have an impact on inflammation and neurodegeneration in the context of HIV infection independent from viral replication. Teri shows a more complete reduction of cytokines CXCL10, CCL2, and IL-6 in the coculture situation whereas MMF predominantly reduces microglia CXCL10 and IL-6 release in the absence of monocytoid cells. CXCL10 and IL-6 are associated with immune activation and crucial for general recruitment of immune cells [28, 29]. CCL2 showed a distinct effect of recruiting HIV-infected leukocytes across the BBB [30]. However, it remains speculative why higher concentrations of both Teri and MMF strongly reduced cytokine secretion but failed to further enhance neuronal viability. Neurodegeneration during HAND is presumably mediated by pleiotropic mechanisms. Our main hypothesis is that activation of innate immune cells is linked with neurodegeneration, independent from viral replication. Therefore, we used secretion of different inflammatory/ neurotoxic cytokines described in the pathogenesis of HAND as markers of activation of innate immune cells. Neurotoxicity assays were employed to demonstrate the functional impact of the cellular activation. In our previous work, we were able to show that cytokines differentially regulated in our model are correlated with neurofilament heavy chain as a marker for neurodegeneration in $\mathrm{HIV}^{+}$patients [4]. However, this does not suggest that cytokines investigated are exclusive mediators of neuronal cell death. Thus, it remains speculative why the higher concentrations of Teri and MMF which were able to reduce cytokine secretion failed to enhance neuronal viability. Rather, our previously published results in conjunction with our present data argue for multifactorial mechanisms, which have anti-inflammatory effects and act beneficially on neuronal survival. Both Teri or MMF act on microglia and monocytes via the inhibition of nuclear factor kappa-light-chain-enhancer $(\mathrm{NF}-\mathrm{kB})$ [31, 32]. It was postulated that Teri reduces mRNA production of pro-inflammatory factors matrix metalloproteinase (MMP) 2 and MMP9 in monocytes [33]. In addition to the inhibition of mitochondrial DHODH, Teri decreased the release of IL-6 and CCL2 
from activated monocytes in vitro, presumably in a DHODH independent manner [11]. Also antiviral properties of Teri have been described, hypothetically mediated by non-specific pyrimidine depletion $[34,35]$. Teri has also an inhibitory effect on the expression of pro-inflammatory IL-6 in the context of Enterovirus 71 infection of the CNS cell line SY-SH5Y [33].

Data from experimental autoimmune encephalomyelitis indicate effects of MMF on microglia to be mainly mediated through activation of hydroxycarboxylic acid receptor 2 (HCAR2), leading to a phenotypic change of microglia with neuroprotective properties [13]. This was also supported by findings in a neuropathy model in rats, in which MMF causes a phenotypic shift from proinflammatory to anti-inflammatory macrophages [36]. However, we did not observe a phenotype change in our model based on secretion of IL-4 and IL-10. In HIV-infected macrophages, MMF upregulates heme oxygenase-1 and reduces glutamate release with reduced neurotoxicity [14]. Furthermore, it has been reported that MMF reduces cART-mediated neurotoxicity in pigtail macaques and rats [37].

Whereas we aimed at investigating effects of wellcharacterized agents approved for neuroimmunological disease on innate immune cells in the context of HAND, both agents used target lymphocytes. In addition, clinical relevance of these medications might be restricted due to adverse drug reactions in combination with cART (e.g., pancytopenia and hepatotoxicity). However, also HIV-infected $\mathrm{T}$ cells are implied in the pathogenesis of HAND (e.g., IFN- $\gamma$ expressing $\mathrm{CD}^{+} \mathrm{T}$ cells) [38], clearly arguing for complex neuroimmunological interactions. In a first short clinical trial teriflunomide did not lead to a detectable decrease of $\mathrm{CD}^{+}{ }^{+}$or $\mathrm{CD}^{+}$cells in cART untreated $\mathrm{HIV}^{+}$patients [39]. Immunotherapy might especially be feasible in patients with high $\mathrm{CD}_{4}^{+}$cell counts, which can be achieved with early initiation of sufficient antiretroviral therapy [40].

Targeting enhanced inflammation in the context of HAND is promising, considering that this chronic immune activation is not eliminated by cART, which instead acts by lowering viral load [8]. Effects of Teri and MMF on cytokine levels may have implications for subsequent recruitment of inflammatory cells to the CNS [28, 41-43] and aggravation of neurodegeneration $[44,45]$. Besides its function in recruiting cells and establishing an inflammatory environment, high levels of IL-6 cause sleep onset insomnia [46, 47], which could in part explain asymptomatic neurocognitive impairment in HAND [48].

In addition to targeting cytokine secretion, other therapeutic mechanisms have been proposed in the context of HAND. Treatment with FK506 has been shown to reduce mitochondrial injury and neurodegeneration in gp120 transgenic mice [49]. Another approach is the modulation of monocytoid cells via statin-treatment. Statins reduce expression of CD163, which has been related to neurotoxicity in HAND and also reduces secretion of the chemoattractant CCL2 [50].

New treatment approaches are urgently needed to attenuate HAND with its potentially devastating impact on quality of life [51]. It is expected that HAND will in future pose a high socioeconomic burden due to higher life expectancy of HIV-infected patients and increase of severity of HAND over time. Our study demonstrates that inflammatory mechanisms of innate immunity known to be involved in neurodegeneration can be modulated by agents approved in autoimmune neuroinflammation, leading to reduced neurotoxicity. Further research is warranted to understand molecular mechanisms involved in HAND with the goal to better target compartmentalized inflammation and neurodegeneration.

\section{Additional files}

Additional file 1: Figure S1. Co-culture secretion of cytokines is elevated compared to mono-culture secretion. The co-culture of microglial cells with HIV vector-transduced monocytoid cells (left side of the panels) induced a more pronounced release of CXCL10, CCL5, CCL2, and IL-6 compared to the microglial/monocytoid mono-culture. Distinct from treatment in co-culture, MMF significantly decreased release of CXCL10 and IL-6 in HMC3 mono-culture treated with HIV vector whereas treatment with $30 \mu \mathrm{M}$ Teri had no effect. Shown are three to six independent experiments performed in triplicates. Significance is shown in comparison to HMC3 in co-culture with HIV vector-transduced monocytoid cells $\left(^{* * *}\right)$ or in comparison to HMC3 mono-culture with HIV vector (+++) or in comparison to U937 mono-culture with HIV vector (\#\#). Data are shown as mean \pm SEM. Statistical analysis was performed using one-way ANOVA $(<0.0001)$ with Tukey's multiple comparison test as post hoc analysis. ${ }^{*} p<0.05 ;{ }^{* *} / \# \# p<0.01 ;{ }^{* * *} /+++p<0.001$. (TIF $799 \mathrm{~kb}$ )

Additional file 2: Figure S2. Cytotoxic potential of Teri and MMF on monocytoid cells and microglial cells. Treatment of monocytoid cells (A) or microglial cells (B) did not lead to cell death using concentrations of up to $30 \mu \mathrm{M}$ of Teri and up to $100 \mu \mathrm{M}$ MMF in monocytoid cells (A) or up to $100 \mu \mathrm{M}$ Teri and $1000 \mu \mathrm{M}$ MMF in microglial cells (B). Treatment was performed for $24 \mathrm{~h}$ before analysis. Cell death was determined using 7-Aminoactinomycin D (7AAD) in FACS analysis (A) or Hoechst/7AAD

co-staining (B). Three independent experiments performed in triplicates. Significance is shown in comparison to untreated monocytoid cells (A) or untreated HMC3 cells (B). Data are shown as mean \pm SEM. Statistical analysis was performed using one-way ANOVA $(<0.0001)$ with Tukey's multiple comparison test as post hoc analysis. ${ }^{* *} p<0.001$ (A). For HMC3, ANOVA showed no difference (B). (TIF $259 \mathrm{~kb}$ )

\section{Abbreviations}

CART: Combined antiretroviral therapy; CSF: Cerebrospinal fluid; DHODH: Dihydroorotate dehydrogenase; DMSO: Dimethylsulfoxide; FCS: Fetal calve serum; HAND: HIV-associated neurocognitive disorder; HCAR2: Hydroxycarboxylic acid receptor 2; HFN: Human fetal neurons; HIV: Human immunodeficiency virus; HMC3: Human microglial cell line 3; MAP-2: Microtubule-associated protein-2; MEM: Minimal essential media; MMF: Monomethylfumarate; MMP: Matrix metalloproteinase; NFH: Neurofilament heavy chain; NFK $\beta$ : Nuclear factor kappa-light-chain-enhancer; Nrf2: Nuclear factor 2; Pen/Strep: Penicillin/streptomycin; Teri: Teriflunomide 


\section{Acknowledgements}

We are thankful to all patients who gave permission to use their brain tissue for experiments. We appreciate the technical assistance of Fatima Arakrak. We thank Dr. Jennifer Pocock, University College London, for providing HMC3 cells and Dr. V. Wee Yong for support with laboratory facilities of the University of Calgary. We acknowledge the use of the microscopy "RUN CORE" facility of the Foothills Hospital, University of Calgary. We acknowledge the support by the Open Access Publication Funds of the Ruhr-University Bochum. SF is supported by a research award of the Medical Faculty of the Ruhr-University Bochum. We thank Dr. Jason R. Plemel, University of Calgary, for proofreading of the manuscript

\section{Funding}

Initial funding was provided by the Faculty of medicine, Ruhr-University Bochum (FORUM F859-2015).

\section{Availability of data and materials}

The datasets analyzed during the current study are available from the corresponding author on reasonable request.

\section{Authors' contributions}

BA and SF designed the study, conducted the experiments, analyzed the data, and wrote the manuscript. KS conducted the experiments and revised the manuscript. MvL provided the tissue. TG revised the manuscript. RG revised the manuscript. BG designed the study and revised the manuscript. AC designed and supervised the study and wrote the manuscript. All authors read and approved the final manuscript.

\section{Competing interests}

B. A. received travel grants from Novartis, not related to this manuscript. S. F. received travel grants from Biogen Idec and Genzyme, not related to this manuscript.

K. S. is employed by Biogen, Ismaningen, Germany, not related to this manuscript.

M. v. L. has nothing to declare.

T. G. has nothing to declare.

R. G. serves on scientific advisory boards for Teva Pharmaceutical Industries Ltd., Biogen Idec, Bayer Schering Pharma, and Novartis; has received speaker honoraria from Biogen Idec, Teva Pharmaceutical Industries Ltd., Bayer Schering Pharma, and Novartis; serves as editor for Therapeutic Advances in Neurological Diseases and on the editorial boards of Experimental Neurology and the Journal of Neuroimmunology; and receives research support from Teva Pharmaceutical Industries Ltd., Biogen Idec, Bayer Schering Pharma, Genzyme, Merck Serono, and Novartis, none related to this manuscript. B. G. has nothing to declare.

A. C. received personal compensation as a speaker or consultant for Bayer, Biogen, Sanofi-Genzyme, Merck, Novartis, Roche and Teva Neuroscience. He also received research support from Biogen, Genzyme and Novartis, none related to this manuscript.

\section{Consent for publication}

Not applicable.

\section{Ethic approval and consent to participate}

Experiments with primary human microglia were approved by the ethics committee of the Ruhr-University Bochum (No. 13-4821). Experiments with human embryonic neurons were approved by the conjoint health research ethics board at the University of Calgary. Donors provided written informed consent for research use of brain tissue; the laboratory team did not have access to the medical record.

\section{Publisher's Note}

Springer Nature remains neutral with regard to jurisdictional claims in published maps and institutional affiliations.

\section{Author details}

'Department of Neurology, St. Josef-Hospital, Ruhr-University Bochum, Gudrunstr. 56, 44791 Bochum, Germany. ${ }^{2}$ Hotchkiss Brain Institute and Department of Clinical Neurosciences, University of Calgary, Calgary, Alberta, Canada. ${ }^{3}$ Department of Neurology, University Hospital Bern and University of Bern, Bern, Switzerland. ${ }^{4}$ Department of Neurosurgery,
Knappschaftskrankenhaus Bochum, In der Schornau 22-25, 44892 Bochum, Germany. ${ }^{5}$ Fraunhofer Institute for Cell Therapy and Immunology, Leipzig, Germany. ${ }^{6}$ Department of Molecular and Medical Virology, Ruhr-University Bochum, Universitätsstr. 150, 44801 Bochum, Germany.

\section{Received: 23 September 2016 Accepted: 28 February 2017 \\ Published online: 11 March 2017}

\section{References}

1. Heaton RK, Clifford DB, Franklin Jr DR, Woods SP, Ake C, Vaida F, Ellis RJ, Letendre SL, Marcotte TD, Atkinson JH, et al. HIV-associated neurocognitive disorders persist in the era of potent antiretroviral therapy: CHARTER Study. Neurology. 2010;75:2087-96.

2. Peluso MJ, Spudich S. Treatment of HIV in the CNS: effects of antiretroviral therapy and the promise of non-antiretroviral therapeutics. Curr HIV/AIDS Rep. 2014;11:353-62.

3. Gonzalez-Scarano F, Martin-Garcia J. The neuropathogenesis of AIDS. Nat Rev Immunol. 2005;5:69-81.

4. Faissner S, Ambrosius B, Schanzmann K, Grewe B, Potthoff A, Munch J, Sure U, Gramberg T, Wittmann S, Brockmeyer N, et al. Cytoplasmic HIV-RNA in monocytes determines microglial activation and neuronal cell death in HIVassociated neurodegeneration. Exp Neurol. 2014;261:685-97.

5. Block ML, Zecca L, Hong JS. Microglia-mediated neurotoxicity: uncovering the molecular mechanisms. Nat Rev Neurosci. 2007;8:57-69.

6. Hagberg L, Cinque P, Gisslen M, Brew BJ, Spudich S, Bestetti A, Price RW, Fuchs D. Cerebrospinal fluid neopterin: an informative biomarker of central nervous system immune activation in HIV-1 infection. AIDS Res Ther. 2010;7:15.

7. Kamat A, Lyons JL, Misra V, Uno H, Morgello S, Singer EJ, Gabuzda D. Monocyte activation markers in cerebrospinal fluid associated with impaired neurocognitive testing in advanced HIV infection. J Acquir Immune Defic Syndr. 2012;60:234-43.

8. Airoldi M, Bandera A, Trabattoni D, Tagliabue B, Arosio B, Soria A, Rainone V, Lapadula G, Annoni G, Clerici M, Gori A. Neurocognitive impairment in HIVinfected naive patients with advanced disease: the role of virus and intrathecal immune activation. Clin Dev Immunol. 2012;2012:467154.

9. McGuire JL, Gill AJ, Douglas SD, Kolson DL. Central and peripheral markers of neurodegeneration and monocyte activation in HIV-associated neurocognitive disorders. J Neurovirol. 2015;21:439-48.

10. Bar-Or A, Pachner A, Menguy-Vacheron F, Kaplan J, Wiendl H. Teriflunomide and its mechanism of action in multiple sclerosis. Drugs. 2014;74:659-74.

11. Li L, Liu J, Delohery T, Zhang D, Arendt C, Jones C. The effects of teriflunomide on lymphocyte subpopulations in human peripheral blood mononuclear cells in vitro. J Neuroimmunol. 2013;265:82-90.

12. Linker RA, Lee DH, Ryan S, van Dam AM, Conrad R, Bista P, Zeng W, Hronowsky X, Buko A, Chollate S, et al. Fumaric acid esters exert neuroprotective effects in neuroinflammation via activation of the Nrf2 antioxidant pathway. Brain. 2011;134:678-92.

13. Parodi B, Rossi S, Morando S, Cordano C, Bragoni A, Motta C, Usai C, Wipke BT, Scannevin RH, Mancardi GL, et al. Fumarates modulate microglia activation through a novel HCAR2 signaling pathway and rescue synaptic dysregulation in inflamed CNS. Acta Neuropathol. 2015;130:279-95.

14. Gill AJ, Kovacsics CE, Cross SA, Vance PJ, Kolson LL, Jordan-Sciutto KL, Gelman BB, Kolson DL. Heme oxygenase-1 deficiency accompanies neuropathogenesis of HIV-associated neurocognitive disorders. J Clin Invest. 2014:124:4459-72.

15. Cross SA, Cook DR, Chi AW, Vance PJ, Kolson LL, Wong BJ, Jordan-Sciutto $\mathrm{KL}$, Kolson DL. Dimethyl fumarate, an immune modulator and inducer of the antioxidant response, suppresses HIV replication and macrophagemediated neurotoxicity: a novel candidate for HIV neuroprotection. J Immunol. 2011;187:5015-25.

16. Janabi N, Peudenier S, Heron B, Ng KH, Tardieu M. Establishment of human microglial cell lines after transfection of primary cultures of embryonic microglial cells with the SV40 large T antigen. Neurosci Lett. 1995;195:105-8.

17. Etemad S, Zamin RM, Ruitenberg MJ, Filgueira L. A novel in vitro human microglia model: characterization of human monocyte-derived microglia. J Neurosci Methods. 2012;209:79-89.

18. Jadhav VS, Krause KH, Singh SK. HIV-1 Tat C modulates NOX2 and NOX4 expressions through miR-17 in a human microglial cell line. J Neurochem. 2014;131:803-15.

19. Chan A, Seguin R, Magnus T, Papadimitriou C, Toyka KV, Antel JP, Gold R. Phagocytosis of apoptotic inflammatory cells by microglia and its 
therapeutic implications: termination of CNS autoimmune inflammation and modulation by interferon-beta. Glia. 2003;43:231-42.

20. Sundstrom C, Nilsson K. Establishment and characterization of a human histiocytic lymphoma cell line (U-937). Int J Cancer. 1976;17:565-77.

21. Vecil GG, Larsen PH, Corley SM, Herx LM, Besson A, Goodyer CG, Yong WW. Interleukin-1 is a key regulator of matrix metalloproteinase-9 expression in human neurons in culture and following mouse brain trauma in vivo. J Neurosci Res. 2000;61:212-24.

22. Soneoka Y, Cannon PM, Ramsdale EE, Griffiths JC, Romano G, Kingsman SM, Kingsman AJ. A transient three-plasmid expression system for the production of high titer retroviral vectors. Nucleic Acids Res. 1995;23:628-33.

23. Naldini L, Blomer U, Gallay P, Ory D, Mulligan R, Gage FH, Verma IM, Trono D. In vivo gene delivery and stable transduction of nondividing cells by a lentiviral vector. Science. 1996;272:263-7.

24. Cavrois M, De Noronha C, Greene WC. A sensitive and specific enzymebased assay detecting HIV-1 virion fusion in primary $T$ lymphocytes. Nat Biotechnol. 2002;20:1151-4

25. Bagasra O, Lavi E, Bobroski L, Khalili K, Pestaner JP, Tawadros R, Pomerantz RJ. Cellular reservoirs of HIV-1 in the central nervous system of infected individuals: identification by the combination of in situ polymerase chain reaction and immunohistochemistry. Aids. 1996;10:573-85.

26. Sloka S, Zhornitsky S, Silva C, Metz LM, Yong WW. 1,25-Dihydroxyvitamin D3 protects against immune-mediated killing of neurons in culture and in experimental autoimmune encephalomyelitis. PLoS One. 2015;10:e0144084.

27. Yuan L, Qiao L, Wei F, Yin J, Liu L, Ji Y, Smith D, Li N, Chen D. Cytokines in CSF correlate with HIV-associated neurocognitive disorders in the postHAART era in China. J Neurovirol. 2013:19:144-9.

28. Kolb SA, Sporer B, Lahrtz F, Koedel U, Pfister HW, Fontana A. Identification of a T cell chemotactic factor in the cerebrospinal fluid of HIV-1-infected individuals as interferon-gamma inducible protein 10. J Neuroimmunol. 1999;93:172-81.

29. Sorensen TL, Trebst C, Kivisakk P, Klaege KL, Majmudar A, Ravid R, Lassmann H, Olsen DB, Strieter RM, Ransohoff RM, Sellebjerg F. Multiple sclerosis: a study of CXCL10 and CXCR3 co-localization in the inflamed central nervous system. J Neuroimmunol. 2002;127:59-68.

30. Eugenin EA, Osiecki K, Lopez L, Goldstein H, Calderon TM, Berman JW. CCL2/monocyte chemoattractant protein-1 mediates enhanced transmigration of human immunodeficiency virus (HIV)-infected leukocytes across the blood-brain barrier: a potential mechanism of HIV-CNS invasion and NeuroAIDS. J Neurosci. 2006;26:1098-106.

31. Breedveld FC, Dayer JM. Leflunomide: mode of action in the treatment of rheumatoid arthritis. Ann Rheum Dis. 2000;59:841-9.

32. Tsubaki M, Ogawa N, Takeda T, Sakamoto K, Shimaoka H, Fujita A, Itoh T, Imano M, Satou T, Nishida S. Dimethyl fumarate induces apoptosis of hematopoietic tumor cells via inhibition of NF-kappaB nuclear translocation and downregulation of BCI-XL and XIAP. Biomed Pharmacother. 2014;68:999-1005.

33. Huang JL, Wu SY, Xie XJ, Wang MX, Zhu S, Gu JR. Inhibiting effects of Leflunomide metabolite on overexpression of CD147, MMP-2 and MMP-9 in PMA differentiated THP-1 cells. Eur J Pharmacol. 2011;670:304-10.

34. Teschner S, Gerke P, Geyer M, Wilpert J, Krumme B, Benzing T, Walz G. Leflunomide therapy for polyomavirus-induced allograft nephropathy: efficient BK virus elimination without increased risk of rejection. Transplant Proc. 2009;41:2533-8.

35. Bernhoff E, Tylden GD, Kjerpeseth $\sqcup$, Gutteberg TJ, Hirsch HH, Rinaldo $\mathrm{CH}$. Leflunomide inhibition of BK virus replication in renal tubular epithelial cells. J Virol. 2010;84:2150-6.

36. Han R, Xiao J, Zhai H, Hao J. Dimethyl fumarate attenuates experimental autoimmune neuritis through the nuclear factor erythroid-derived 2-related factor 2/hemoxygenase-1 pathway by altering the balance of M1/M2 macrophages. J Neuroinflammation. 2016;13:97.

37. Akay C, Cooper M, Odeleye A, Jensen BK, White MG, Vassoler F, Gannon PJ, Mankowski J, Dorsey JL, Buch AM, et al. Antiretroviral drugs induce oxidative stress and neuronal damage in the central nervous system. J Neurovirol. 2014;20:39-53.

38. Schrier RD, Hong S, Crescini M, Ellis R, Perez-Santiago J, Spina C, Letendre S. Cerebrospinal fluid (CSF) CD8+ T-cells that express interferon-gamma contribute to HIV associated neurocognitive disorders (HAND). PLoS One. 2015;10:e0116526.

39. Read SW, DeGrezia M, Ciccone EJ, DerSimonian R, Higgins J, Adelsberger JW, Starling JM, Rehm C, Sereti I. The effect of leflunomide on cycling and activation of T-cells in HIV-1-infected participants. PLoS One. 2010;5:e11937.
40. Lundgren JD, Babiker AG, Gordin F, Emery S, Grund B, Sharma S, Avihingsanon A, Cooper DA, Fatkenheuer G, Llibre JM, et al. Initiation of antiretroviral therapy in early asymptomatic HIV infection. N Engl J Med. 2015:373:795-807.

41. Lake JE, Vo QT, Jacobson LP, Sacktor N, Miller EN, Post WS, Becker JT, Palella Jr FJ, Ragin A, Martin E, et al. Adiponectin and interleukin-6, but not adipose tissue, are associated with worse neurocognitive function in HIV-infected men. Antivir Ther. 2015;20:235-44.

42. Conductier G, Blondeau N, Guyon A, Nahon JL, Rovere C. The role of monocyte chemoattractant protein MCP1/CCL2 in neuroinflammatory diseases. J Neuroimmunol. 2010;224:93-100.

43. Yadav A, Collman RG. CNS inflammation and macrophage/microglial biology associated with HIV-1 infection. J Neuroimmune Pharmacol. 2009:4:430-47.

44. Sui Y, Stehno-Bittel L, Li S, Loganathan R, Dhillon NK, Pinson D, Nath A, Kolson D, Narayan O, Buch S. CXCL10-induced cell death in neurons: role of calcium dysregulation. Eur J Neurosci. 2006;23:957-64.

45. Nixon DE, Landay AL. Biomarkers of immune dysfunction in HIV. Curr Opin HIV AIDS. 2010;5:498-503.

46. Gay CL, Zak RS, Lerdal A, Pullinger CR, Aouizerat BE, Lee KA. Cytokine polymorphisms and plasma levels are associated with sleep onset insomnia in adults living with HIV/AIDS. Brain Behav Immun. 2015;47:58-65.

47. Wirth MD, Jaggers JR, Dudgeon WD, Hebert JR, Youngstedt SD, Blair SN, Hand GA. Association of markers of inflammation with sleep and physical activity among people living with HIV or AIDS. AIDS Behav. 2015;19:1098-107.

48. Byun E, Gay CL, Lee KA. Sleep, fatigue, and problems with cognitive function in adults living with HIV. J Assoc Nurses AIDS Care. 2016;27:5-16.

49. Fields JA, Overk C, Adame A, Florio J, Mante M, Pineda A, Desplats P, Rockenstein E, Achim C, Masliah E. Neuroprotective effects of the immunomodulatory drug FK506 in a model of HIV1-gp120 neurotoxicity. J Neuroinflammation. 2016;13:120.

50. Yadav A, Betts MR, Collman RG. Statin modulation of monocyte phenotype and function: implications for HIV-1-associated neurocognitive disorders. J Neurovirol. 2016;22:584-96.

51. Nasi M, De Biasi S, Gibellini L, Bianchini E, Pecorini S, Bacca V, Guaraldi G, Mussini C, Pinti M, Cossarizza A. Ageing and inflammation in patients with HIV infection. Clin Exp Immunol. 2017;187:44-52.

\section{Submit your next manuscript to BioMed Central and we will help you at every step:}

- We accept pre-submission inquiries

- Our selector tool helps you to find the most relevant journal

- We provide round the clock customer support

- Convenient online submission

- Thorough peer review

- Inclusion in PubMed and all major indexing services

- Maximum visibility for your research

Submit your manuscript at www.biomedcentral.com/submit
Biomed Central 